\title{
PHYSICAL FITNESS AMONG 6TH GRAD STUDENTS AND EVALUATION WITH THE NORMATIVE REFERENCE VALUES
}

\author{
Eilin Sepp, Eva-Maria Riso, Sille Vaiksaar, Maret Pihu \\ Institute of Sport Sciences and Physiotherapy, University of Tartu, Tartu, Estonia
}

\begin{abstract}
The objective of this study was to compare Estonian 6th grade students' physical fitness level with normative values from ALPHA fitness test and international normative $20 \mathrm{~m}$ shuttle run values. The following healthrelated fitness components were assessed: cardiorespiratory fitness, flexibility, muscular strength, muscular endurance and speed, as a skillrelated fitness component. Physical fitness results were evaluated with the ALPHA health-related fitness test battery for children and adolescents and with normative $20 \mathrm{~m}$ shuttle run values. Students from 6th grade $(n=178)$ participated in the study. Physical fitness performance was not significantly different between boys and girls, except for flexibility and upper body muscle strength and endurance. Boys' percentage in very low and low level was higher on every test compared to girls' results based on normative values. The results of the research indicate the importance to measure the physical fitness of schoolchildren and to compare them with the evaluation scales to plan and carry out more PE lessons focusing on physical fitness development. Further research is needed to evaluate students' physical fitness levels among different age groups. Physical fitness development is urgently needed and should be included in school curriculum.
\end{abstract}

Keywords: health- and skill related fitness components; physical fitness tests; development of physical abilities 


\section{INTRODUCTION}

Physical fitness can be considered as an integrated measure of most body functions (skeletomuscular, cardiorespiratory, hematocirculatory, psychoneurological and endocrine-metabolic) involved in the performance of daily physical activity and/or physical exercise. Thereafter, when physical fitness is tested, the functional status of all these systems is actually being checked. This is the reason why physical fitness is stated one of the most important health markers [14]. It is necessary that children and youth are sufficiently engaged in physical activity. In addition, the physical education (PE) lessons would be support the formation of healthy lifestyle. Although the knowledge of physical activity benefits, the level of physical fitness has decreased during last decade among both adults and youth [3].

Less than 25\% of Estonian children and youth meet the WHO recommendation of at least $60 \mathrm{~min}$ daily moderate-to-vigorous physical activity (MVPA) [12, 16, 20]. In the recent study of Cooper et al. [5], it was found that in all 20 studied countries only $9 \%$ boys and 1.9\% 5-17-year-old girls met the guidelines of achieving 60 min of MVPA every day. Daily physical activity tends to decrease during puberty [6]. Physical activity influences the level of physical abilities. Physical abilities can be divided as health-related and skill-related [1]. Physical activity and physical abilities are closely associated with the level of health-related fitness components: cardiorespiratory endurance, muscle strength and endurance, flexibility and body composition, which are important in coping with daily activities and help to prevent chronical diseases [17]. Skill-related physical abilities as balance, coordination, speed of movements, speed of reaction, power and speed of locomotion are associated with motor competence [7].

Evaluation of the level of physical abilities is an essential part of study process in PE to give feedback to student and teacher. Knowing and analysing the level of physical fitness helps to set goals to develop children's physical abilities. The aim this study was to compare the $6^{\text {th }}$ grade students' physical fitness level with normative values from ALPHA fitness tests and international normative $20 \mathrm{~m}$ shuttle run values.

\section{MATERIALS AND METHODS}

\section{Participants}

One hundred and seventy-eight $12-13$-years-old $6^{\text {th }}$ grade students (92 girls and 86 boys) from Tartu and Tallinn participated in this study. Written informed consents from parent and child were obtained from all 
participants. The study was approved by the Medical Ethics Committee of the University of Tartu, Tartu, Estonia, approval no 265/T-15.

\section{Procedures}

Internationally accepted, time-saving and easily available physical fitness tests were carried out in school settings. Following health-related physical abilities were measured: cardiorespiratory fitness, flexibility, muscle strength of upper and lower body and muscle strength endurance of upper body. Speed of running was evaluated as skill-related physical ability. Physical fitness tests based on ALPHA fitness program were applied [17]. For evaluation of cardiorespiratory endurance, $20 \mathrm{~m}$ shuttle run test was used [19]. Table 1 describes the specific tests used.

Table 1.

\begin{tabular}{|c|c|c|c|c|}
\hline & Physical ability & Test & Evaluated parameter & $\begin{array}{l}\text { Result regist- } \\
\text { ration units }\end{array}$ \\
\hline 1. & $\begin{array}{l}\text { Cardio- } \\
\text { respiratory } \\
\text { fitness }\end{array}$ & $\begin{array}{l}20 \text { m shuttle run } \\
\text { according to audio } \\
\text { signals }\end{array}$ & $\begin{array}{l}\text { Cardiorespiratory } \\
\text { endurance }\end{array}$ & $\begin{array}{l}\text { Number of laps } \\
\text { run }\end{array}$ \\
\hline 2. & $\begin{array}{l}\text { Strength of } \\
\text { lower limbs }\end{array}$ & $\begin{array}{l}\text { Standing long } \\
\text { jump }\end{array}$ & $\begin{array}{l}\text { Explosive strength of } \\
\text { leg muscles }\end{array}$ & Centimetres \\
\hline 3. & $\begin{array}{l}\text { Muscle } \\
\text { endurance of } \\
\text { upper body }\end{array}$ & $\begin{array}{l}\text { Hang on the } \\
\text { horizontal bar with } \\
\text { flexed hands }\end{array}$ & $\begin{array}{l}\text { Muscle endurance of } \\
\text { upper body }\end{array}$ & Seconds \\
\hline 4. & $\begin{array}{l}\text { Muscle } \\
\text { strength of } \\
\text { upper body }\end{array}$ & $\begin{array}{l}\text { Handgrip strength } \\
\text { measurement with } \\
\text { dynamometer }\end{array}$ & Handgrip strength & Kilograms \\
\hline 5. & $\begin{array}{l}\text { Speed of } \\
\text { running }\end{array}$ & $4 \times 10 m$ shuttle run & $\begin{array}{l}\text { Speed, agility, speed of } \\
\text { reaction and changing } \\
\text { the direction of } \\
\text { moving }\end{array}$ & Seconds \\
\hline 6. & Flexibility & $\begin{array}{l}\text { Back-saving flexion } \\
\text { in sitting position }\end{array}$ & $\begin{array}{l}\text { Flexibility of lower back } \\
\text { and hamstring muscles }\end{array}$ & Centimetres \\
\hline
\end{tabular}

All tests were applied twice and the best values of two attempts were used in the analyses, except the 20-m shuttle run and hanging on the bar test that were only conducted once. Flexibility and handgrip tests was performed with both limbs and the average of results was calculated. Warm-up was carried out before testing. The technical performance of tests was observed carefully to guarantee the reliability and comparability of results. 


\section{Statistical analysis}

Data analysis was made using the SPSS version 20.0 for Windows (SPSS, Inc., Chicago, IL, USA). Descriptive statistics are presented as mean and standard deviations. All variables were checked for normality before the analysis. Group differences between means were analysed with independent t-test. Spearman correlation analysis was used to find associations between measured parameters. Chi-square test was used to compare categorical values. Significance was set at $p<0.05$. The data were compared with the physical fitness evaluation scales $[13,19]$.

\section{RESULTS}

Table 2 demonstrates the data of physical fitness testing and differences between the results of boys and girls. Boys exceeded girls significantly in muscle strength and endurance of upper body as the girls showed significantly better flexibility. The average results of tests to assess cardiorespiratory fitness, strength of lower limbs and speed of running did not differ in comparison of boys and girls.

Table 2. Description of study sample, the average results and differences of results between boys and girls.

\begin{tabular}{lccc}
\hline & $\begin{array}{c}\text { Whole sample } \\
(\mathrm{n}=178)\end{array}$ & $\begin{array}{c}\text { Boys } \\
(\mathrm{n}=86)\end{array}$ & $\begin{array}{c}\text { Girls } \\
(\mathrm{n}=92)\end{array}$ \\
\hline Age (years) & $\begin{array}{c}12.5 \pm 0.50 \\
(\mathrm{n}=178)\end{array}$ & $12.6 \pm 0.49$ & $12.4 \pm 0.49$ \\
\hline Flexibility (cm) & $\begin{array}{c}23.12 \pm 8.71 \\
(\mathrm{n}=162)\end{array}$ & $17.47 \pm 7.04$ & $27.77 \pm 7.05^{*}$ \\
\hline Standing long jump (cm) & $\begin{array}{c}162.07 \pm 24.01 \\
(\mathrm{n}=164)\end{array}$ & $165.95 \pm 24.78$ & $158.73 \pm 22.95$ \\
\hline Handgrip strength $(\mathrm{kg})$ & $\begin{array}{c}24.39 \pm 5.00 \\
(\mathrm{n}=168)\end{array}$ & $25.22 \pm 5.29$ & $23.68 \pm 4.64^{*}$ \\
\hline Speed of running 4x10 $\mathrm{m}$ (sec) & $\begin{array}{c}13.04 \pm 1.22 \\
(\mathrm{n}=161)\end{array}$ & $12.98 \pm 1.42$ & $13.08 \pm 1.02$ \\
\hline Hanging on horizontal bar (sec) & $\begin{array}{c}9.05 \pm 9,99 \\
(\mathrm{n}=160)\end{array}$ & $10.82 \pm 10.96$ & $7.51 \pm 8.84^{*}$ \\
\hline Cardiorespiratory fitness (laps) & $37.91 \pm 16.96$ & $39.46 \pm 18.26$ & $36.35 \pm 15.49$ \\
\hline
\end{tabular}

${ }^{*} \mathrm{p}<0.05$ as compared with boys 
Associations between the parameters of physical abilities are demonstrated in Table 3. Positive association was found between cardiorespiratory fitness and muscular strength of lower body, as well as with muscular endurance of upper body (Table 3). The strength of lower body was positively associated with both strength and muscular endurance of upper body. Speed of running as skill-related physical ability had no positive association with healthrelated physical abilities. No positive associations were found between flexibility and the other health-related physical abilities (Table 3).

Table 3. Associations between parameters of physical abilities

\begin{tabular}{lcccccc}
\hline & 1. & 2. & 3. & 4. & 5. & 6. \\
\hline 1. Strength of lower body & 1 & & & & & \\
\hline 2. Flexibility & 0.034 & 1 & & & & \\
\hline 3. Strength of upper body & $0.253^{* *}$ & -0.057 & 1 & & & \\
\hline 4. Speed of running & $-0.704^{* *}$ & 0.004 & -0.113 & 1 & & \\
\hline $\begin{array}{l}\text { 5. Muscular endurance of } \\
\text { upper body }\end{array}$ & $0.510^{* *}$ & -0.006 & 0.080 & $-0.483^{* *}$ & 1 & \\
\hline \begin{tabular}{l} 
6. Cardiorespiratory fitness \\
\hline
\end{tabular} & $0.548^{* *}$ & 0.057 & -0.002 & $-0.577^{* *}$ & $0.572^{* *}$ & 1 \\
\hline
\end{tabular}

${ }^{* *} \mathrm{p}<0.01$

The proportions of students on different physical fitness levels is depicted in Table 4. The evaluation scales of Ortega et al. [13] and Tomkinson et al. [19] were used to find the proportions of students on different physical fitness levels. Significantly more boys than girls (12.4 vs $23.3 \%$ ) were on very low level in flexibility test (Table 4). At the same time, nearly $37 \%$ of girls and $19 \%$ of boys showed very high level in flexibility test. The strength of lower body was measured using standing long jump test. More than half (42\%) of participated girls achieved very high level (Table 4 ). In the test of evaluating the strength of upper body $9 \%$ of boys reached very high level as nearly half of boys were on low and very low level. More than one third of boys (35\%) showed very low level in running speed, while $1.4 \%$ of them were on very high level in this test (Table 4). Simultaneously nearly $15 \%$ of girls reached very high level in running speed. In the muscular endurance of upper body about $22 \%$ of both boys and girls were on the highest level and same proportion of students stayed on the lowest level. More than half of girls achieved high and very high result in cardiorespiratory fitness test which is significantly higher proportion than among boys (Table 4). 
Table 4. The proportions of students on different physical fitness levels

\begin{tabular}{|c|c|c|c|c|c|}
\hline Physical fitness level & Very low & Low & Medium & High & Very high \\
\hline \multicolumn{6}{|l|}{ Flexibility* } \\
\hline Boys ( $n=73 ; \%)$ & 23.3 & 19.2 & 17.8 & 20.5 & 19.2 \\
\hline Girls ( $n=89 ; \%)$ & $12.4 \#$ & 11.2 & 16.8 & 22.5 & 37.1\# \\
\hline \multicolumn{6}{|c|}{ Strength of lower body* } \\
\hline Boys ( $n=76 ; \%)$ & 11.8 & 14.5 & 21.1 & 32.9 & 19.7 \\
\hline Girls ( $n=88 ; \%)$ & 3.4 & 9.1 & 22.7 & $22.8 \#$ & 42 \\
\hline \multicolumn{6}{|c|}{ Strength of upper body* } \\
\hline Boys ( $n=78 ; \%)$ & 21.8 & 30.8 & 24.3 & 14.1 & 9 \\
\hline Girls (n=90; \%) & 21.1 & $17.8 \#$ & 23.3 & 18.9 & 18.9 \\
\hline \multicolumn{6}{|l|}{ Speed of running* } \\
\hline Boys $(n=74 ; \%)$ & 35.1 & 27.1 & 21.6 & 14.8 & 1.4 \\
\hline Girls ( $n=87 ; \%)$ & 12.6\# & 26.5 & 26.4 & 19.6 & 14.9\# \\
\hline \multicolumn{6}{|c|}{ Muscular endurance of upper body* } \\
\hline Boys $(n=74 ; \%)$ & 22.7 & 26.6 & 18.7 & 10.7 & 21.3 \\
\hline Girls ( $n=86 ; \%)$ & 22.1 & 17.4 & 22.1 & 15.1 & 23.3 \\
\hline \multicolumn{6}{|c|}{ Cardiorespiratory fitness ${ }^{* *}$} \\
\hline Boys $(n=76 ; \%)$ & 25 & 23.7 & 26.3 & 10.5 & 14.5 \\
\hline Girls ( $n=75 ; \%)$ & $6.7 \#$ & 20 & 18.6 & 21.4\# & 33.3\# \\
\hline
\end{tabular}

*evaluation is based on Ortega et al 2011; **evaluation is based on Tomkinson et al 2016 \#significantly different $(p<0.05)$ as compared with boys

\section{DISCUSSION}

The aim of this study was to evaluate the level of physical fitness among 6th grade students and to compare the results with the recommended evaluation scales $[13,19]$. The results of the study are important to assess the health status of children and to give feedback to students and teachers. Physical fitness of 11-17 years old adolescents was evaluated by EUROFIT tests in Estonia and Lithuania 1998 [8] and since that survey, the data of physical fitness of Estonian schoolchildren are scarce.

As comparing the average results of boys and girls it is not unexpected that the boys exceeded girls in upper body strength and endurance (Table 2). 
The girls had significantly better results in flexibility which could be explained with different preferences in sport and free time activities of both genders (Table 2). Our results support the findings of Ortega et al 2011 [13].

Several health-related physical abilities were significantly associated with each other in our study (Table 3). Positive associations were registered between cardiorespiratory fitness and muscular strength of lower body, as well as with muscular endurance of upper body (Table 3). The strength of lower body was positively associated with both strength and muscular endurance of upper body (Table 3). These findings would explain the importance of many-sided physical training in childhood and youth. Speed of running as skill-related physical ability had no positive association with healthrelated physical abilities. Unexpectedly, we found no positive associations between flexibility and the other health-related physical abilities (Table 3). However, flexibility is important physical ability ensuring the amplitude of movements [9]. Non-sufficient flexibility of joints disturbs the performance and can lead to injuries [9]. Thus, the importance of developing flexibility should be more emphasized among basic school students, especially among boys.

Based on the standards of Ortega et al. [13], the testing results of healthrelated physical abilities can be associated with the health status. Very low and low level of certain ability gives a signal that the person can be in health risk and developing this ability would be urgently needed. Results on the medium and higher level are recommended from the standpoint of good health [13]. As compared the proportions of students in different physical fitness levels the worst performance was observed in hanging on the horizontal bar. Even $34 \%$ of participants did not reach the result and from the remained students $49 \%$ of boys and $39 \%$ of girls achieved very low or low result (Table 4). The usefulness of this test in this age group can be stated questionable because also the results of previous studies $[2,13]$ were low among numerous participants. The results of our study participants remain weaker in most tests than those in the study of Jürimäe and Volbekiene [8] almost two decades ago.

Cardiorespiratory endurance is considered to be one of the most important health-related physical fitness components [18]. High level of cardiorespiratory fitness in childhood and youth is strongly associated with better cardiorespiratory health in later age [13,17]. Using reliable and valid $20 \mathrm{~m}$ shuttle run according to audio signals is effective to test students while running together helps to motivate children and achieve better results $[18,19]$. The result of test is expressed as number of laps run. The results of our study show low aerobic capacities of participants which could be associated with 
low physical activity. Nearly half (49\%) of boys and almost one fourth (27\%) of girls reached very low or low result (Table 4). One third (33\%) of girls and $14.5 \%$ of boys showed very high cardiorespiratory fitness level (Table 4 ). The big discrepancy could be explained by the remarkable difference of standards: to reach the medium level the boys have to run 39 laps but girls only 25 laps.

As in several previous studies $[4,8,11]$ our girls showed significantly better results in flexibility than boys. The very high level was achieved by $37 \%$ of girls and $19 \%$ of boys while $43 \%$ of boys and $24 \%$ of girls reached very low and low level (Table 4). Flexibility should be more developed in PE lessons to prevent injuries and maintain normal movement amplitude.

Strength is necessary physical ability in developing speed, coordination and flexibility. Strength exercises enable to prevent osteoporosis, regulate body weight, diminish the effect of risk factors of diabetes and cardiorespiratory diseases [15]. The explosive strength of leg muscles was evaluated with the result of standing long jump in our study. As compared with other tests performed the smallest proportion of students achieved very low results $12 \%$ of boys and $3.4 \%$ of girls. On the other hand, $42 \%$ of girls and nearly $20 \%$ of boys showed very high level in standing long jump (Table 4 ). Still the results are significantly lower than those in the previous study of Jürimäe and Volbekiene [8]. The health status of muscles, nerves, joints and bones could be evaluated by assessment of upper body muscular strength [18]. Among adults an association has been found between coping with daily activities and upper body muscular strength [10]. More than half of our boys showed very low or low level of upper body muscular strength. However, the results of girls were almost equally distributed between all levels (Table 4).

The speed of running as skill-related physical ability was negatively associated with the health-related physical abilities (Table 3 ). Few boys (1.4\%) reached the very high level and $35 \%$ of boys were on the very low level (Table 4). Among the girls almost 15\% reached the very low level and $12.6 \%$ the highest level.

The sample number was the limiting factor of this study. Still it can be concluded that remarkable proportion of participated students were on the low or very low level of cardiorespiratory fitness, muscular strength of upper body and flexibility. More boys were on very low or low fitness level than girls in all physical fitness tests. As compared with the study carried out two decades ago the nowadays children achieved weaker results. Attention should be paid on the physical activity and developing of physical abilities among Estonian children. 


\section{ACKNOWLEDGEMENTS}

The authors thank the children, teachers and schools for their participation in the study, as well as the entire data collection team.

\section{REFERENCES}

1. Caspersen CJ, Powell KE, Christenson GM. (1985) Physical activity, exercise, and physical fitness: definitions and distinctions for health-related research. Pub Health Reports, 100(2): 126-131

2. Castro-Pinero J, Artero EG, Espana-Romero V, Ortega FB, Sjöström M, Suni J, Ruiz JR. (2010) Criterion-related validity of field-based fitness tests in youth: a systematic review. Br J Sports Med, 44(13): 934-943

3. Catley MJ, Tomkinson GR. (2013) Normative health-related fitness values for children: analysis of 85347 test results on 9-17-year-old Australians since 1985. Br J Sports Med, 47:98-108

4. Chen W, Mason S, Hammond-Bennett A, Zalmout S. (2016) Manipulative skill competency and health-related physical fitness in elementary school students. J Sports Health Sci, 5:491-499

5. Cooper AR, Goodman A, Page AS, Sherar LB, Dale WE. Van Sluijs EMF, Andersen LB, Anderssen S, Cardons G, Davey R, Froberg K, Hallal P, Janz KF, Kordas K, Kreimler S, Pate RP, Puder JR, Reilly JJ, Salmon J, Sardinha LB, Timperio A, Ekelund U. (2015). Objectively measured physical activity and sedentary time in youth: The International children's accelerometry database (ICAD). Int J Behav Nutr Phys Act, 12:113

6. Guinhouya BC, Samouda H, de Beaufort C. (2013) Level of physical activity among children and adolescents in Europe: a review of physical activity assessed objectively by accelerometry. Public Health, 127:301-11

7. Jeng SC, Chang CW, Liu WY, Hou YJ, Lin YH. (2017) Exercise training on skillrelated physical fitness in adolescents with intellectual disability: a systematic review and meta- analysis. Disability and Health J, 10(2): 198-206

8. Jürimäe T, Volbekiene V. (2006) Eurofit test results in Estonian and Lithuanian 11 to 17- year-old children: a comparative study. Europ J Phys Ed, 3(2): 178-184

9. Knudson DV, Magnusson P, McHugh M. (2000) Current issues in flexibility fitness. President's Council on Physical Fitness and Sports Research Digest, 3(10): 2-9

10. Metter EJ, Talbot LA, Schrager M, Conwit R. (2002) Skeletal muscle strength as a predictor of all-cause mortality in healthy men. J Gerontol Biol Sci Med Sci 2002, 57(10): 359- 365

11. Miguel-Etayo PD, Gracia-Marco L, Ortega FB, Intenmann T, Foraita R, Lissner L, Oja L, Barba G, Michels N, Tornaitis M, Molnár D, Pitsiladis Y, Ahrens W, 
Moreno LA, IDEFICS consortium. (2014) Physical fitness reference standards in European children: the IDEFICS study. Int J Obes, 57-66

12. Mooses K, Mäestu J, Riso EM, Hannus A, Mooses M, Kaasik P, Kull M. (2016) Different methods yielded two-fold difference in compliance with physical activity on school days. PLoS ONE, 11(3) e0152323

13. Ortega FB, Aretro EG, Ruiz JR, Espana-Romero V, Jiemenez- Pavon D, Vicente-Rodriguez G, Moreno LA, Manios Y, Béghin L, Ottevaere C, Ciarapica D, Sarri K, Dietrich S, Blair SN, Kersting M, Molnár D, González-Gross M, Gutierrez A, Sjöström M, Castillo MJ, HELENA study. (2011) Physical fitness levels among European adolescents: the Helena study. Br J Sports Med, 45:20-29

14. Ortega FB, Ruiz RJ, Castillo MJ, Sjöström M. (2008) Physical fitness in childhood and adolescence: a powerful marker of health. Int J Obes, 32:1-11

15. Ratamess NA, Alvar BA, Evetoch TK, Hoish TJ, Kibler WB. (2009) Progression models in resistance training for healthy adults. Med Sci Sports Exerc, 41: $687-708$

16. Riso EM, Kull M, Mooses K, Hannus A, Jürimäe J. (2016) Objectively measured physical activity levels and sedentary time in 7-9-year-old Estonian schoolchildren: independent associations with body composition parameters. BMC Public Health, 16:346

17. Ruiz JR, Castro-Piñero J, España-Romero V, Artero EV, Ortega FB, Cuenca MM, Jimenéz-Pavón D, Chillón P, Girela-Rejón MJ, Mora J, Gutierrez A, Suni J, Sjöström M, Castillo MJ. (2011) Field-based fitness assessment in young people: the ALPHA health-related fitness test battery for children and adolescents. Br J Sports Med, 45:518-524

18. Ruiz JR, Ortega FB, Gutierrez A, Castillo MJ (2006) Health-related fitness assessment in childhood and adolescence: a European approach based on the AVENA, EYHS and HELENA studies. J Publ Health, 14: 269-277

19. Tomkinson GR, Lang JJ, Tremblay MS, Dale M, LeBlanc AG, Belanger K, Ortega FB, Léger L. (2016) International normative $20 \mathrm{~m}$ shuttle run values from 1142026 children and youth representing 50 countries. Br J Sports Med 2016; 1-14

20. WHO (World Health Organization). Global recommendations on physical activity for health.2010.

\section{Correspondence to:}

Eva-Maria Riso

Institute of Sport Sciences and Physiotherapy,

University of Tartu, Estonia

5 Jakobi St, Tartu, Estonia 51014

Tel: +37253880147

E-mail: eva-maria.riso@ut.ee 